\title{
REMOÇÃO DE CORANTE CATIÔNICO DE MEIO AQUOSO USANDO RESÍDUO DA AGROINDÚSTRIA DE ALIMENTOS COMO ADSORVENTE
}

\author{
L. M. da $\operatorname{SILVA}^{1}$, N. M. da $\operatorname{SILVA}^{3}$, U. A. R. $\operatorname{SILVA}^{2}$, A. O. e $\operatorname{SOUZA}^{3}$ \\ ${ }^{1}$ Universidade Estadual Paulista, Departamento de Engenharia de Alimentos \\ ${ }^{2}$ Universidade Federal de Uberlândia, Faculdade de Engenharia Química \\ ${ }^{3}$ Universidade Estadual do Sudoeste da Bahia \\ * email: luefs@yahoo.com.br
}

\begin{abstract}
RESUMO
A poluição de efluentes por corantes sintéticos é um grande problema, uma vez que podem ser tóxicos e afetar as atividades de fotossíntese devido à redução da penetração da luz solar. A adsorção é comprovadamente um excelente método para tratar efluentes contendo corantes. Além de ser um processo de fácil operação e alta eficiência, facilmente aplicável, ambientalmente correto e economicamente viável, principalmente quando são utilizados adsorventes de baixo custo. Estudos têm sido direcionados na busca por adsorventes alternativos, também chamados de bioadsorventes ou adsorventes não convencionais. Partindo-se deste pressuposto, objetivou-se utilizar semente de goiaba (G) resíduo agroindustrial, como adsorvente para remoção do corante violeta cristal em meio aquoso. A partir do estudo adsortivo verificou-se que a capacidade máxima de adsorção é de cerca de $96,87 \%$, valor considerado alto quando comparado a outros bioadsorventes. A biomassa foi caracterizada por análise térmica (TG e DTA), espectroscopia no infravermelho com transformada de Fourier (FTIR) e determinação da composição química. Os espectros no infravermelho evidenciaram a presença dos grupos $\mathrm{OH}$ e $\mathrm{COOH}$ que são sítios ativos para adsorção de corantes catiônicos. A remoção de poluentes hídricos utilizando este material apresentou bons resultados nas condições de estudo, indicando que o mesmo pode vir a se constituir como uma alternativa viável e eficiente para o tratamento de efluentes industriais.
\end{abstract}

\section{INTRODUÇÃO}

Corantes são compostos químicos que podem conectar-se nas superfícies ou tecidos para conferir cor. A maioria dos corantes são moléculas orgânicas complexas e são resistentes a muitas interações. Corantes sintéticos são amplamente utilizados em muitos campos de tecnologia como por exemplo, em indústrias têxtil, de papel, curtimento de couro, de processamento de alimentos, plásticos, cosméticos, borracha, impressão e indústria que fabricam corantes alimentícios (MUSTAFA, 2014).

A geração de efluentes contaminados com corantes provenientes de diferentes atividades continua preocupando a comunidade científica e empresarial.

À medida que as pesquisas e os processos industriais avançam a geração desses contaminantes cresce vertiginosamente. Em contrapartida, os órgãos de fiscalização estão exigindo a redução de forma sustentável de modo que os produtos industriais beneficiem a população sem agredir o meio ambiente (BAZZO, 2015).

O corante catiônico violeta cristal (VC) ou violeta genciana avaliado nesta pesquisa, atua como agente identificador de bactérias, possui atividade antisséptica e antimicótica, sendo, por isto, empregado em 
desinfetantes de intensidade moderada. Em hospitais tem aplicação para o tratamento de queimaduras sérias e outras lesões da pele e gengivas. No Brasil é encontrado também em rações para aves, assim como para carimbar cortes de carne em matadouros. Sabe se inda que o violeta cristal pode estar sendo usado na condição de corante alimentício em aguardentes de mandioca (GOES, 2013).

As descargas de águas com resíduos de corantes podem aumentar consideravelmente os níveis de poluição devido à sua natureza recalcitrante, o que poderá conferir cor indesejável ao corpo de água reduzindo a penetração da luz solar, consequentemente prejudicando a fotossíntese no meio aquático, além de reduzir o oxigênio dissolvido dificultando o desenvolvimento das espécies aquáticas. (BAZZO, 2015).

A adsorção tem sido relatada como um excelente método para tratar efluentes contendo corantes, oferecendo significantes vantagens em relação aos métodos convencionais, tais como; oxidação química e redução, precipitação física e floculação, fotólise, tratamento eletroquímico, osmose reversa, bioacumulação e / ou biodegradação (KANT, 2012). Muitas indústrias têxteis usam carvão ativado comercial para o tratamento de resíduos de corante, o qual possui elevado valor econômico, sendo assim, muitos estudos têm se concentrados em encontrar alternativas ao carvão ativado comercial que possua um menir custo, mas com efetivo potencial adsorvente. Muitos pesquisadores têm relatado a viabilidade da utilização de vários adsorventes de baixo custo derivados de materiais naturais, resíduos sólidos industriais, subprodutos agrícolas e bioadsorventes como precursores (ALI et al, 2012).

Esses bioadsorventes podem ser cascas, sementes ou caroços oriundos da biomassa corriqueiramente tratados como resíduos e não tem valor de mercado. $\mathrm{O}$ baixo custo desses produtos aliado à sua boa capacidade de adsorção vem tornando-os em uma alternativa viável e eficaz para remoção de corantes, fármacos, pesticidas, hormônios e metais pesados em efluentes industriais (BAZZO, 2015).

As propriedades de adsorção de sementes, cascas e caroços são relatadas costumeiramente na forma de materiais carbonizados. Pereira (2014), por exemplo utilizou cascas de cacau e de seriguela como precursores de carvão ativado os quais foram utilizados na adsorção de proteína bovina de soro de leite. A forma não carbonizada de resíduos agroindustriais pode ser investigada uma vez que não existe relato que estes possuam baixa eficiência de adsorção.

Considerando que o Brasil é um importante produtor de frutas e que $o$ processamento de grande parcela dessas frutas gera elevada quantidade de resíduos sólidos muitas vezes descartados de forma inadequada, por possuir baixo valor agregado, o objetivo do presente trabalho foi utilizar sementes de goiaba, resíduos da agroindústria de alimentos, com vistas a remoção do corante violeta cristal presente em efluentes industriais através de processo de adsorção.

\section{MATERIAL E MÉTODOS}

\subsection{Tratamento da biomassa}

As sementes de goiaba foram cedidas por uma unidade de produção de polpa de fruta localizada na região Sudoeste da Bahia. As sementes chegaram ainda úmida ao laboratório. Foi então lavado com água para a separação dos resíduos e depois secas ao sol por 48 horas, seguida, por secagem em estufa a $60^{\circ} \mathrm{C}$ (Tecnal TE 393/1) por 24h. Os materiais foram triturados em processador doméstico, moídos em moinho de facas para obtenção de partículas com tamanho entre 0,5 $\mathrm{mm}-1,70 \mathrm{~mm}$.

\subsection{Composição química da biomassa}

A composição química das amostras foi determinada a partir das análises de umidade, cinzas, proteína bruta, fibra bruta, gordura total e carboidratos.

As análises foram realizadas de acordo com métodos descritos pela Association of 
Official Analytical Chemists (AOAC, 1984)

Todas as análises foram realizadas em triplicata.

\subsection{Caracterização física da biomassa}

Espectroscopia de Infravermelho com Transformada de Fourier (FTIR)

É um tipo de espectroscopia de absorção que utiliza a região do infravermelho do espectro eletromagnético. É uma técnica que pode ser usada para identificar um composto ou investigar a composição de uma amostra.

A análise de FTIR foi realizada em um espectrômetro de infravermelho Spectrum 100 da marca Perkin Elmer, na Faculdade de Química do Departamento de Ciências Exatas e da Terra da Faculdade de Química da Universidade do Estado da Bahia - UNEB. Os espectros de absorção no Infravermelho foram obtidos sob forma de pastilha de $\mathrm{KBr}(0,05 \%)$ e na região de 4000 a $400 \mathrm{~cm}^{-1}$

Análise Térmica Diferencial $e$ Termogravimétria (TG/DTA)

Análise Térmica consiste num grupo de técnicas na qual a quantidade de material degradado, decomposto da substância e/ou de seus produtos de reação, utilizando-se miligramas até gramas da amostra, é medida em função da temperatura, enquanto a substancia é submetida a uma variação de temperatura controlada e programada. A técnica baseia-se, portanto, na evolução térmica de um determinado material durante a carbonização que pode ser acompanhada por meio de termogramas experimental e diferencial (TG e DTG) (ROCHA, 2006)

As medidas de análise termogravimétrica foram realizadas em equipamento Shimadzumodelo DTG $-60 \mathrm{H}$ e para os experimentos de DTA utilizou-se o equipamento da Shimadzu DTG 60-A. Ambas as medidas foram conduzidas nas seguintes condições de operação: Taxa de aquecimento $10{ }^{\circ} \mathrm{C} / \mathrm{min}$, vazão de nitrogênio gasoso 50
$\mathrm{mL} / \mathrm{min}$, desde a temperatura de $30^{\circ} \mathrm{C}$ até 1000 ${ }^{\circ} \mathrm{C}$.

\subsection{Experimentos de adsorção}

Aproximadamente $0,01 \mathrm{~g}$ do resíduo foi adicionado em tubos contendo $5 \mathrm{~mL}$ da solução violeta cristal (Violeta cristal água destilada), na concentração de $100 \mathrm{mg}$. L ${ }^{-1}$. Os tubos foram colocados sob agitação constante (em aparato experimental), por tempos de 5, $15,30,60,120,240$ até 480 minutos, em temperatura ambiente, e em seguida foram centrifugados (Centrífuga MPW-350), sendo o sobrenadante retirado filtrado utilizando filtro de seringa de PTFE hidrofílico, poro 0,45 um, diâmetro do filtro $25 \mathrm{~mm}$ (Analítica). A quantificação do corante restante na solução foi realizada por leitura direta em espectrofotômetro (Biochrom Libra S70) no comprimento de onda de $583 \mathrm{~nm}$. A partir dos valores de absorbância das soluções lidos no espectrofotômetro e da curva de calibração, determinou-se a capacidade adsortiva do bioadsorvente, utilizando a Equação 1.

$q e=\frac{(C o-C e q) \cdot V}{W}$

A eficiência do processo adsortivo foi obtida a partir dos valores de concentração inicial e final da solução, conforme a Equação 2.

efic $=\left(\frac{V C_{i n}-V C_{e q}}{V C_{i n}}\right) x 100$

\section{RESULTADOS E DISCUSSÃO}

\subsection{Caracterização química}

Os resultados da composição química da biomassa podem ser observados na Tabela 1

Tabela 1 Composição química da semente de goiaba $(\mathrm{G})$

\begin{tabular}{lc}
\hline Parâmetro (\%) & $\begin{array}{l}\text { Semente de Goiaba - } \\
\text { G }\end{array}$ \\
\hline Umidade & $8,1320 \pm 0,063$
\end{tabular}


Cinzas

$1,364 \pm 0,019$

Proteína Bruta

$1,122 \pm 0,026$

Carboidratos

$27,987 \pm 0,762$

Gordura total

$9,586 \pm 0,379$

Fibra Bruta

$53,591 \pm 0,708$

Fonte: Autor (2015)

\subsection{Caracterização física da biomassa}

Espectroscopia no infravermelho com transformada de Fourier

A capacidade de adsorção em materiais vegetais é atribuída aos grupos ativos presentes neles. Com isso, realizaramse as medidas de espectroscopia no infravermelho visando uma avaliação qualitativa preliminar dos principais grupos funcionais presentes na biomassa estudada. Os espectros no infravermelho obtidos estão ilustrados na Figura 1

Figura 1 - Espectro da região do infravermelho das sementes de goiaba

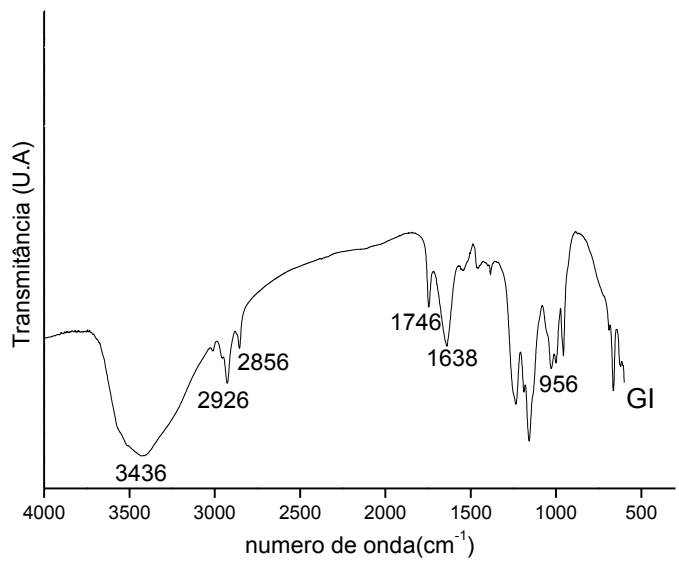

Fonte: Autor (2015)

O espectro infravermelho na região de 4000 a $400 \mathrm{~cm}^{-1}$ referentes à semente de goiaba está ilustrado na Figura 1. Considerando o espectro, notou-se uma banda larga e pouco intensa localizada por volta de $3400 \mathrm{~cm}^{-1}$ e uma banda estreita centrada em $1600 \mathrm{~cm}^{-1}$ que podem ser atribuídas aos modos de estiramento $(\mathrm{O}-\mathrm{H})$ e à deformação $(\mathrm{H}-\mathrm{O}-\mathrm{H})$ das moléculas de água adsorvidas na superfície do material respectivamente.
Verificou-se ainda, quatro bandas centradas em $3023 \mathrm{~cm}^{-1}, 1642 \mathrm{~cm}^{-1} 1086 \mathrm{~cm}^{-1}$ e $720 \mathrm{~cm}^{-1}$ referente ao grupo alceno, duas bandas fortes em $2927 \mathrm{~cm}-1$ e $2851 \mathrm{~cm}^{-1}$ relacionadas ao grupo alcano $\left(\mathrm{CH}_{2}\right)$ e uma pico forte e outro médio respectivamente em $1453 \mathrm{~cm}^{-1}$ e em $1376 \mathrm{~cm}^{-1}$ referente ao alcano $\left(\mathrm{CH}_{3}\right)$ e alguns picos fortes em $1750 \mathrm{~cm}^{-1}, 1230 \mathrm{~cm}^{-1}$ e 1163 $\mathrm{cm}^{-1}$ referente ao éster.

\section{Análise termogravimétrica $(T G)$}

$\mathrm{O}$ resultado de $\mathrm{TG}$ da semente de goiaba (Figura 2) evidenciou perda de massa acentuada da temperatura ambiente até $600^{\circ} \mathrm{C}$. $\mathrm{O}$ primeiro evento de perda de massa, observado em temperaturas mais baixas (entre 25 e $300^{\circ} \mathrm{C}$ ), pode ser atribuído à perda de água adsorvida e outras espécies voláteis. A perda de massa observada em temperaturas mais altas (acima de $300^{\circ} \mathrm{C}$ ) pode ser atribuída à degradação da biomassa. Acima de $650^{\circ} \mathrm{C}$, não foi observado mais nenhum evento térmico indicando a estabilidade térmica da estrutura carbonácea formada.

Figura 2 - Curva Termogravimétrica (TG) da semente de goiaba.

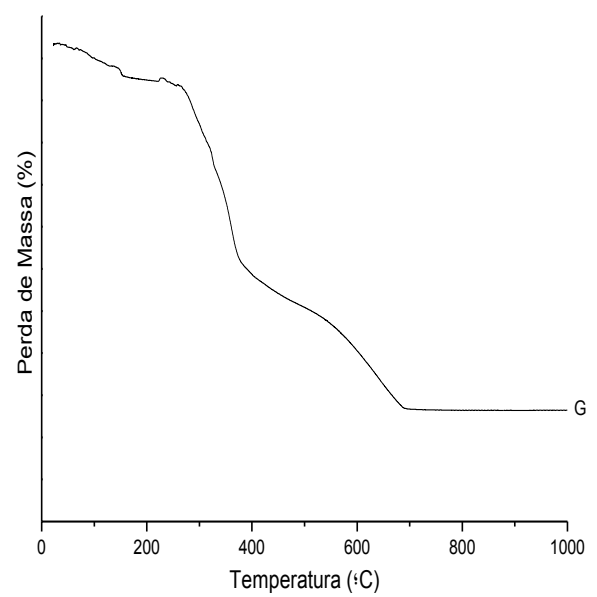

Fonte: Autor (2015)

Resultados de Análise Térmica Diferencial (DTA)

A Figura 3 ilustra os resultados de DTA obtidos. De acordo com a curva térmica, 
da semente de goiaba verifica-se que o evento de saída de água, indicado no resultado de TG, não foi evidenciado no DTA. Tal evento deveria ser sinalizado por um pico endotérmico em temperaturas próximas a 100 ${ }^{\circ} \mathrm{C}$. Esse comportamento confirma a baixa umidade das amostras (Tabela 1). Notou-se ainda um pico endotérmico em torno de 350$380^{\circ} \mathrm{C}$, que pode ser atribuído à liberação de voláteis oriundos da decomposição dos compostos orgânicos. Verificou-se também um pico exotérmico fraco em $450{ }^{\circ} \mathrm{C}$ e um pico exotérmico intenso em $600{ }^{\circ} \mathrm{C}$ para que podem ser associados à combustão da celulose, hemicelulose e lignina.

Figura 3 Analise Térmica Diferencial (DTA)

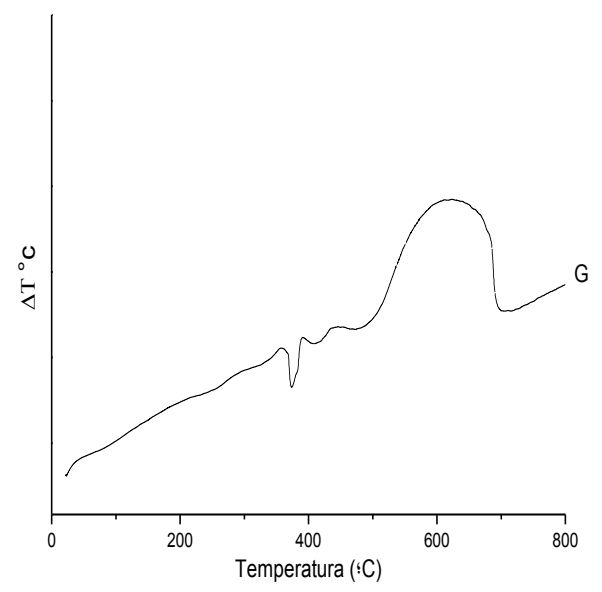

Fonte: Autor (2015)

\subsection{Estudo Cinético}

A cinética de adsorção buscou analisar o comportamento experimental da capacidade de adsorção do adsorvente em função do tempo de contato com o adsorvato.

Adicionou-se $5 \mathrm{ml}$ de solução do violeta cristal $(100 \mathrm{mg} / \mathrm{L})$ em contato dinâmico com $0,1 \mathrm{~g}$ dos adsorventes por tempos de 5, 10, 15, 30, 60, 120, 240, 420 minutos. Os resultados são apresentados nas Figura 4. Considerando os resultados dos ensaios cinéticos, verificou-se que a as alterações da concentração do VC, em função do tempo, ocorreu em duas fases. A primeira fase envolveu uma rápida adsorção de corante durante os primeiros $5 \mathrm{~min}$ de contato sorbato- sorvente, que foi seguido por uma fase lenta de remoção de corante, que durou por um período mais longo de tempo (> $60 \mathrm{~min}$ ) até que o equilíbrio fosse alcançado. A fase rápida poderia ser atribuída à rápida ocupação de sítios de sorção da superfície externa, facilmente acessíveis e a possível disponibilidade abundante de sítios ativos no adsorvente, enquanto que com a ocupação gradual desses sítios o processo de adsorção se torna mais lento durante a segunda fase (WANG et al, 2015)

A remoção rápida do adsorbato e o alcance do equilíbrio em um período curto de tempo, quando comparado com outros processos que atingem o equilíbrio em até 48h, são uma das indicações que o adsorvente investigado é eficiente e podem vir a se constituir em alternativa promissora para o tratamento de efluentes tornando o processo mais econômico.

Figura 4 - Cinética de adsorção do corante violeta cristal com a amostra $G$

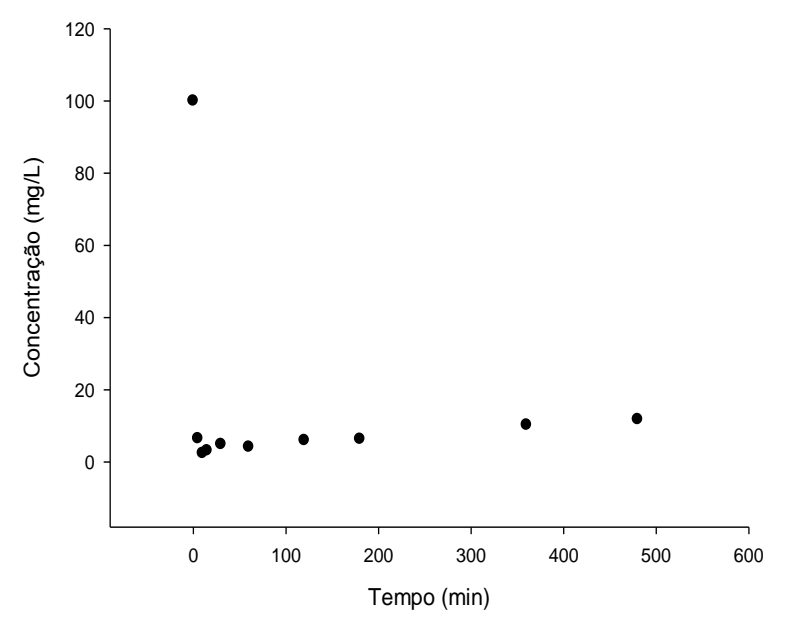

Fonte: Autor (2015)

Tabela 2 - Eficiência do processo de adsorção para biomassa de goiaba

\begin{tabular}{cc}
\hline Tempo (min) & Eficiência $(\%)$ \\
\hline 5 & 95,14 \\
10 & 97,56 \\
15 & 96,87 \\
30 & 95,13 \\
60 & 95,55 \\
120 & 93,69
\end{tabular}




\begin{tabular}{rr}
240 & 93,69 \\
480 & 88,24 \\
\hline
\end{tabular}

Fonte Autor (2015:)

\section{CONCLUSÃO}

A partir dos resultados obtidos verificou-se que a semente de goiaba apresentou um excelente desempenho na adsorção do corante violeta cristal, podendo vir a se constituir numa alternativa promissora para o tratamento de efluentes industriais.

\section{NOMENCLATURA}

$A b s=$ absorbância (adimensional)

$C_{0}=$ concentração inicial de adsorbato na fase fluida $(\mathrm{mg} / \mathrm{L})$

$C e=$ concentração de equilíbrio do soluto na fase fluida $(\mathrm{mg} / \mathrm{L})$

Ceq= concentração de equilíbrio de adsorbato (mg/L)

Cref $=$ qualquer concentração de equilíbrio da fase líquida.

$\mathrm{CV}=$ Violeta Cristal

DTA = Análise Térmica Diferencial

Efic $=$ Eficiência

FTIR = Infravermelho com Transformada de

Fourier.

$\mathrm{G}=$ Pó da semente de goiaba

$\min =$ minutos

$T=$ temperatura da mistura $\left({ }^{\circ} \mathrm{C}\right)$

$\mathrm{TG}=$ Termograma

$V=$ volume da solução $(\mathrm{L})$

$W=$ massa de adsorvente $(\mathrm{g})$.

\section{REFÊNCIAS}

ALI, I., ASIM, M., KHAN, T.A. Low cost adsorbents for the removal of organic pollutants from wastewater. Journal of Environmental Management, v. 113, p. 170-183, 2012.

ASSOCIATION OF OFFICIAL ANALYTICAL CHEMISTS. Official methods of analysis. 14th ed. Arlington, 1984.
BAZZO, A. Aplicação e caracterização do caroço de abacate (Persea americana mil) como adsorvente na remoção do corante violeta cristal. 2015. 71p. Dissertação (Mestrado em Ciências dos Materiais) Universidade Federal do Rio Grande do Sul, Porto Alegre. 2015.

GOES, M. C. C. Palha de Carnaúba (Copernicia cerifera) como removedor dos corantes azul de metileno e violeta cristal. 2013. 102p. Dissertação (Mestrado em Química) - Universidade Federal do Maranhão, São Luís. 2013.

KANT, R.. Adsorption of dye eosin from an aqueous solution on two different samples of activated carbon by static batch method. Journal of Water Resource \& Protection, v. 4, p. 93-98, 2012.

MUSTAFA T. Y, TUSHAR K. S. SHARMEEN A, ANG, H.M. Dye and its removal from aqueous solution by adsorption: A review. Advances in Colloid and Interface Science. Volume 209, July 2014, p. 172-184.

PAVAN, F.A.; LIMA, I.S.; LIMA, E.C.; AIROLDI, C.; GUSHIKEM Y. Use of ponkan mandarin peels as biosorbent for toxic metals uptake from aqueous solutions. Journal of Hazardous Materials. v. 137, p. 527-533, 2006.

PEREIRA, R. G., et al. Preparation of activated carbons from cocoa shells and siriguela seeds using $\mathrm{H}_{3} \mathrm{PO}_{4}$ and $\mathrm{ZnCL}_{2}$ as activating agents for BSA and $\alpha$-lactalbumin adsorption. Fuel Processing Technology. v 126, p. 476-486, 2014.

WANG, S., ZIMMERAN, A. R., LI, Y., MA, L., HARRIS, W. G., MIGLIACCIO, K. W. Removal of arsenic by magnetic biochar prepared from pinewood and natural hematite. Bioresouce Technology. v.175, p 391-395. 2015. 


\section{AGRADECIMENTOS}

Ao CNPq pela concessão de bolsa de estudos e a Universidade Estadual do Sudoeste da Bahia pelo suporte técnico para realização da pesquisa. 